\title{
Reducing Cardiac Fibrosis: Na/K-ATPase Signaling Complex as a Novel Target
}

\author{
Fan $\mathbf{X}$, Xie $\mathbf{J}$ and Tian $\mathbf{J}^{*}$
}

Department of Medicine, Center for Hypertension and Personalized Medicine, University of Toledo, Ohio 43614, USA

\begin{abstract}
Cardiac fibrosis is a common pathological process in cardiac disease and may lead to heart failure. It can also cause sudden death even in those without cardiac symptoms. Tissue fibrosis can be categorized into two categories: replacement fibrosis (also called reparative fibrosis) and reactive fibrosis. In replacement fibrosis, infiltration of inflammatory cells and accumulation of Extracellular Matrix (ECM) proteins are the initial steps in forming scarlike fibrotic tissue after acute cardiac injury and cardiac cell necrosis. Reactive fibrosis can be formed in response to hormonal change and pressure or volume overload. Experimental studies in animals have identified important pathways such as the Renin-Angiotensin-Aldosterone System (RAAS) and the endothelin pathway that contribute to fibrosis formation. Despite the fact that clinical trials using RAAS inhibitors as therapies for reducing cardiac fibrosis and improving cardiac function have been promising, heart failure is still the leading cause of deaths in the United States. Intensive efforts have been made to find novel targets and to develop new treatments for cardiac fibrosis and heart failure in the past few decades. The $\mathrm{Na} / \mathrm{K}-\mathrm{ATPase}$, a canonical ion transporter, has been shown to also function as a signal transducer and prolonged activation of $\mathrm{Na} / \mathrm{K}-\mathrm{ATP}$ ase signaling has been found to promote the formation of cardiac fibrosis. Novel tools that block the activation of $\mathrm{Na} / \mathrm{K}-\mathrm{ATP}$ ase signaling have been developed and have shown promise in reducing cardiac fibrosis. This review will discuss the recent development of novel molecular targets, focusing on the Na/K-ATPase signaling complex as a therapeutic target in treatment of cardiac fibrosis.
\end{abstract}

Keywords: Cardia fibrosis; Na/K-ATPase; Signaling; Therapeutic target

\section{Introduction}

Cardiac fibrosis is a significant health issue and a common pathological process in cardiac disease that eventually leads to heart failure [1]. Both experimental and clinical data have shown that formation of fibrotic scar tissue increases cardiac stiffness, whereas regression of fibrosis improves cardiac function $[2,3]$. Several categories of drugs have been developed to treat cardiac fibrosis and cardiac failure in clinics. However, there remains a major gap in elucidating the mechanisms of cardiac fibrosis and its association with heart failure, which is still the leading cause of deaths in the United States [4]. Therefore, the discovery of novel molecular targets is essential for improving patient outcomes. The $\mathrm{Na} / \mathrm{K}$-ATPase is an important transmembrane protein and is critical for maintaining ion homeostasis across the cell membrane. In the past 20 years, studies have revealed that the $\mathrm{Na} / \mathrm{K}$-ATPase can also complex with neighboring proteins and function as a signaling transducer that regulates a variety of signaling events such as the activation of Src kinase and NFKB, and the generation of reactive oxygen species [5]. Recent studies have further demonstrated that prolonged activation of $\mathrm{Na} / \mathrm{K}$-ATPase signaling promotes cardiac fibroblast proliferation, increased collagen synthesis, and contributes to the pathogenesis of cardiac fibrosis in different animal models. Therefore, components of the $\mathrm{Na} / \mathrm{K}$-ATPase signaling pathway can be novel therapeutic targets in the treatment of cardiac fibrosis and related cardiac diseases. This review will discuss the recent developments in the treatment of cardiac fibrosis with a focus on the findings that $\mathrm{Na} / \mathrm{K}$-ATPase signaling complex is a novel target for drug development.

\section{Mechanisms of Cardiac Fibrosis}

Cardiac fibrosis can be categorized into two types: reactive fibrosis and replacement fibrosis (also called reparative fibrosis) [6]. Replacement fibrosis often occurs after Myocardial Infarction (MI) when large numbers of cardiac myocytes undergo necrosis. Myocyte necrosis triggers a series of events including immune cell infiltration, inflammation, new vessel formation, removal of necrotic tissue, and eventually the replacement of damaged tissue with collagendominated fibrotic tissue that prevents cardiac muscle from rupture [7]. In addition to scar formation at the infarcted area, the remote noninfarcted regions can develop fibrosis in the interstitial spaces, which is referred to as reactive fibrosis or interstitial fibrosis [6,8-10]. Interstitial fibrosis can also occur in disease conditions that often involve the activation of Renin-Angiotensin-Aldosterone System (RAAS) [11-13], endothelin-1 [14-16], TGF- $\beta$ [17-19], TNF- $\alpha[20,21]$, NFKB $[22,23]$, or other profibrotic signaling pathways [24,25].

Cardiac fibroblast proliferation and differentiation into myofibroblasts are important processes in both types of cardiac fibrosis [1,26,27]. Myofibroblasts, the activated cardiac fibroblasts, are considered as the major source that secret collagen and other ECM proteins during the formation of fibrosis [1,28,29]. Molecular markers such as $\alpha$-smooth muscle actin fibroblast-specific protein 1 and periostin were used to label myofibroblasts [1,30-32]. However, these molecular markers may also be expressed in epicardium, vascular smooth muscle, pericytes, endothelial cells, and cardiac muscle cells

*Corresponding author: Jiang Tian, Associate Professor, Department of Medicine, Center for Hypertension and Personalized Medicine, University of Toledo, 3000 Arlington Ave. Mail Stop: 1025 Toledo, Ohio 43614, USA, Tel: 419383-3510; Fax: 419-383-2871; E-mail: Jiang.tian@utoledo.edu

Received January 05, 2017; Accepted January 24, 2017; Published January 31, 2017

Citation: Fan X, Xie J, Tian J (2017) Reducing Cardiac Fibrosis: Na/K-ATPase Signaling Complex as a Novel Target. Cardiovasc Pharm Open Access 6: 204. doi: 10.4172/2329-6607.1000204

Copyright: (C) 2017 Fan X, et al. This is an open-access article distributed under the terms of the Creative Commons Attribution License, which permits unrestricted use, distribution, and reproduction in any medium, provided the original author and source are credited. 
[1]. Additionally, the origin of myofibroblasts that accumulate during fibrosis formation remains elusive. Resident cardiac fibroblasts are considered the major source but other cell types such as vascular endothelial cells, perivascular cells, and progenitor cells have been shown to differentiate into myofibroblasts [1].

The RAAS and TGF- $\beta$ signaling pathways are major factors that are involved in the activation of cardiac fibroblasts and formation of tissue fibrosis. Administration of angiotensin II or aldosterone has been shown to stimulate collagen and other ECM protein expression and secretion from cardiac fibroblasts [33], while inhibition of RAAS by Angiotensin Converting Enzyme (ACE) inhibitors or angiotensin type I receptor blockers (ARBs) attenuates cardiac fibrosis and improves cardiac function [34-36]. Spironolactone, an antagonist of aldosterone is also a potent drug in the treatment of cardiac remodeling that is related with cardiac fibrosis [37]. In the event of an MI, activation of NFKB was observed in different cells and subsequently drives the expression of a large panel of genes $[22,23]$. These genes produce proinflammatory cytokines such as tumor necrosis factor- $\alpha$ (TNF- $\alpha$ ) and interleukin proteins that subsequently help recruit leukocytes and initiate the inflammation responses [7]. Once the necrotic tissue is cleared by leukocytes, neutrophils, and monocytes, inflammation become suppressed and fibrotic tissue formation follows. Several members of the TGF- $\beta$ family are involved in the regulation of inflammation and fibrosis $[18,38]$. The TGF- $\beta 1$ signaling pathway is an important component in the switch from inflammation to fibrosis [39]. The initial reparative fibrosis is beneficial to prevent heart wall rupture, but if this persists, it will eventually cause cardiac remodeling and reduction in cardiac function. In chronic conditions, activation of RAAS, TGF- $\beta$, and other pro-fibrotic signaling pathways can induce interstitial fibrosis in the heart and other organs [13,18,24,40,41]. Cell proliferation promoters such as non-receptor tyrosine kinases were also reported to increase organ fibrosis [42-44]. In addition to these traditional signaling pathways, epigenetic regulation has drawn attention for their regulating role in cardiac fibrosis. Numerous microRNAs were found to be either pro- or anti-fibrotic [45]. Some anti-fibrotic microRNAs such as the miR-29 mciroRNA family directly target the mRNA of several collagen isoforms, fibrilin 1, elastin, and matrix metalloprotease 2 (MMP2) and thus prevent overexpression of these ECM proteins [46-51]. When the anti-fibrotic microRNAs are reduced in disease state, syntheses of collagen and other ECM protein increase and promoting the development of fibrosis. The understanding of microRNA biosynthesis has been greatly advanced in the past decade and represents a promising area for the development of reagents that regulate specific microRNA expression and prevent organ fibrosis.

\section{Treatment Strategies for Cardiac Fibrosis}

Extensive experimental studies using animal models have revealed important pathways and identified specific molecular markers as targets for treatment of cardiac fibrosis. However, the clinical translation of these findings are limited attributing to the lack of validated noninvasive measurement of cardiac fibrosis in patients. Serum levels of procollagen type I C-terminal peptide (PCIP) and procollagen type III $\mathrm{N}$-terminal peptide (PIIINP) were often used as secondary surrogates for assessment of tissue fibrosis [52], but their correlation to cardiac fibrosis and cardiac function has not been validated in the clinical studies. Echocardiography has also been used for assessment of cardiac fibrosis with diastolic dysfunction [53-55]. More accurate methods using cardiac resonance imaging (CMR) and T1 mapping have been recently used clinically to evaluate cardiac fibrosis [56,57]. These new technologies allow for a more direct measurement of cardiac fibrosis and assessment of the drug effects in clinical studies. Several categories of drugs have now been evaluated for their effect on reducing cardiac fibrosis and improving overall cardiac function in certain small size clinical trials.

ACE inhibitors are the most commonly used drugs for treatment of hypertension and heart failure $[35,36,58,59]$. Enalapril was discovered as an ACE inhibitor that decreases levels of angiotensin II and leads to less vasoconstriction and lower blood pressure [35]. It was shown that enalapril can reduce the risk of death by $16 \%$ in patients with reduced ejection fraction $[35,36]$. ARBs have also been shown to reduce cardiac fibrosis in clinical trials [60]. In addition, animal models with pressure overload demonstrated that hypertension was able to induce cardiac fibrosis and lowering blood pressure attenuated cardiac fibrosis [61]. However, a clinical trial comparing different anti-hypertensive drugs showed that only the ACE inhibitor lisinopril reduced cardiac fibrosis measured by collagen volume fraction in tissue biopsies at 6 months after treatment, but hydrochlorothiazide failed to do so [3]. Spironolactone, an antagonist of aldosterone (another major component of RAAS), has also been shown to have potent effects in reducing cardiac fibrosis in clinical studies using serum levels of PICP and PIIINP as surrogate markers of fibrosis [62-64]. In addition to targeting RAAS, other categories of drugs including vasodilators, antiinflammatory and anti-oxidative agents have been tested clinically for their effects on reducing cardiac fibrosis [65].

TGF- $\beta$ and its downstream signaling components Smad proteins are main regulators of collagen synthesis [18]. TGF- $\beta$ is synthesized in many cell types as a large latent complex, which can be activated by a variety of molecules. Thrombospondin-1 (TSP-1) can disrupt the interaction between the latency-associated peptide (LAP) and TGF- $\beta$ resulting in activation of TGF- $\beta$. Active TGF- $\beta$ binds to its receptor and induces expression of Smad 2/3 and phosphorylation of Smad 4 , which are transcription factors $[18,66]$. Activation of the TGF- $\beta$ signaling pathway enhances collagen types I and III synthesis, decrease collagenase expression, and induces integrin expression [67-69]. TGF- $\beta$ was also a common pathway that regulates fibrosis-related microRNA expression $[70,71]$. Drugs targeting TGF- $\beta$ and Smad proteins have been under active development. The Smad 3 inhibitor Halofuginone was shown to ameliorate radiation-induced fibrosis in mice [72]. A prespecified and pooled analysis of phase 3 clinical trials also indicated that the TGF- $\beta$ inhibitor pirfenidone significantly reduced all-cause mortality and pulmonary fibrosis compared to the placebo group [73].

Using a combination of drugs from different categories has been shown to improve the treatment of heart failure. It was found that addition of spironolactone on top of the standard ACE inhibitor treatment decreased frequency of hospitalization due to worsened heart failure by $35 \%$ compared to ACE inhibitor treatment alone. The death rate was also decreased from $46 \%$ to $35 \%$ in spironolactone plus ACE inhibitor treatment [74]. Since aldosterone is a downstream component of RAAS, blocking aldosterone by spironolactone in addition to ACE inhibition was considered unnecessary and may predispose patients to side effects such as serious hyperkalemia [75]. However, studies found that ACE inhibition can only transiently decrease the production of aldosterone [76,77]. Spironolactone was also found to function as an antagonist of $\mathrm{Na} / \mathrm{K}$-ATPase signaling and attenuates cardiac fibrosis in experimental uremic cardiomyopathy [78]. Another important example of drug combination in the treatment of heart failure is the usage of LCZ696, which is composed of the neprilysin inhibitor LBQ657 and valsartan, an ARB drug [79]. A recent clinical study [80] found that LCZ696 reduced the hazard ratio of all-cause mortality and cardiovascular specific mortality compared to enalapril. Neprilysin 
is a neutral endopeptidase, which degrades natriuretic peptides, bradykinin, and adrnomedullin [81-83]. Inhibition of neprilysin may increase the level of natriuretic peptides and thus counter act with the sodium retention and volume overload [83]. In a related study it was also found that the component of neprilysin inhibitor in LCZ696 had no effect on cardiac fibrosis, while the component of ARB in this drug reduces both cardiac fibrosis and hypertrophy [79].

\section{$\mathrm{Na}$ /K-ATPase as a Novel Target for Cardiac Fibrosis}

Despite the current advances in treatments, there remains a major gap in elucidating the mechanisms of cardiac fibrosis and its association with heart failure. Novel pathways and potential drug targets related with tissue fibrosis have been actively studied. A novel signaling pathway, $\mathrm{Na} / \mathrm{K}$-ATPase signaling, has been demonstrated in experimental animal models to contribute to the formation of cardiac fibrosis [84-90]. Reagents developed to target the components of $\mathrm{Na} /$ K-ATPase signaling have shown promising results in ameliorating cardiac fibrosis and improving cardiac functions [91-94].

$\mathrm{Na} / \mathrm{K}-\mathrm{ATPase}$ is a transmembrane protein that was discovered in 1957 by Dr. Skou [95]. It is a major ion transporter that helps maintain homeostasis of $\mathrm{Na}^{+}$and $\mathrm{K}^{+}$concentrations across the cell membrane by hydrolyzing ATP. The Na/K-ATPase a subunit has 10 transmembrane domain and 3 major cytosol domains namely actuator domain (A domain), nucleotide binding domain ( $\mathrm{N}$ domain) and phosphate binding domain (P domain) [96,97]. Digitalis compounds, also called Cardiotonic Steroids (CTS), specifically bind to the extracellular portion of $\mathrm{Na} / \mathrm{K}$-ATPase a subunit and cause a conformational change which inhibits the ion transporting activity and ATP hydrolysis [98]. In addition to its canonical ion transporting function, the $\mathrm{Na} / \mathrm{K}$ ATPase was found to be able to associate with other signaling proteins and function as a signal transducer $[5,99,100]$. Treatment of cells with $\mathrm{Na} / \mathrm{K}-\mathrm{ATP}$ ase ligands induces activation of Src, PI3K, NFkB, Erk, PLC and other signaling pathways as well as the generation of reactive oxygen species [101-104]. We and others have demonstrated that activation of Src, PI3K and NFKB signaling pathways may stimulate cell proliferation and protect cells from death [103,105,106], whereas prolonged activation of these signaling pathways in certain disease models was demonstrated to cause cardiac hypertrophy and fibrosis [84-90]. Digitalis drug such as digoxin have been used for treatment of congestive heart failure for centuries [107-109]. The endogenous digitalis-like compounds were only recognized a few decades ago and their physiological and pathological roles are just starting to be appreciated. It was found that ouabain and Marinobufagenin (MBG) exist in human blood with the same structure as plant-derived and toad gland-derived digitalis compounds, respectively [110-114]. The elevation of circulating levels of these endogenous compounds was reported in heart failure patients and was correlated with the severity of heart dysfunction [111,115-117]. Other diseases such as renal failure [118], preeclampsia [119], myocardial ischemia/infarction [120,121], and diabetes mellitus [122,123] were also observed in association with elevated levels of endogenous compounds in human plasma samples. However, the accurate measurement of endogenous digitalis compounds in human samples still faces big challenges [124].

Kennedy [125] showed that both $5 / 6^{\text {th }}$ Partial Nephrectomy (PNx), which increase endogenous MBG levels, and MBG perfusion caused significant cardiac fibrosis, suggesting that digitalis compounds binding to $\mathrm{Na} / \mathrm{K}$-ATPase contributes to uremic cardiomyopathy. It has also been shown that immunization against MBG attenuated PNxinduced cardiac fibrosis [125]. Elkareh [90] later demonstrated that MBG stimulate procollagen-1 synthesis in rat cardiac fibroblasts and in
MBG-perfused rat heart tissue. Interestingly, this study demonstrated that although it is required for MBG or PNx induced cardiac fibrosis, TGF- $\beta$ and its downstream component Smad $2 / 3$ or Smad 4 were not activated by MBG. The increased procollagen synthesis is rather associated with the activation of Src kinase and increased reactive oxygen species [90]. Further study [126] showed that MBG induces activation of PKC $\delta$ in a pathway involving phosphorylation of Friend leukemia integration-1 (Fli-1). Fli-1 is a transcription factor that negatively regulates collagen mRNA synthesis, while phosphorylation of Fli-1 can cause degradation of Fli- 1 and subsequently induces collagen synthesis [127]. A recent study from our laboratory demonstrated that ouabain and MBG decrease miR-29b-3p, an anti-fibrotic microRNA, and led to an increase in collagen synthesis through a Src-related signaling pathway in cardiac fibroblasts [128]. These pathways may work in concert to stimulate collagen synthesis and fibrosis formation in response to digitalis compound treatment or in conditions of chronic renal dysfunction.

Since rodents express an ouabain-insensitive form of the $\mathrm{Na} / \mathrm{K}$ ATPase $\alpha 1$ subunit, Lingrel and his colleagues made a mutant mouse strain, in which its $\mathrm{Na} / \mathrm{K}$-ATPase al subunit was mutated to be sensitive to ouabain. These mutant mice and the wild type mice were then subjected to Transverse Aortic Coarctation (TAC). It was shown that TAC caused much more severe and earlier cardiac hypertrophy and fibrosis in mutant mice compared to that in wild type mice [85]. In the same study, they found that treatment with Digibind, a Fab fragment of an ovine anti-digoxin antibody, could prevent the development of cardiac fibrosis and hypertrophy in these animals. A more recent study demonstrated that a digitalis compound potentiates the myofibroblast differentiation through increased COX-2 expression and activation of PKA [129]. These studies clearly showed that $\mathrm{Na} / \mathrm{K}$ ATPase and its ligands are involved in the formation of cardiac fibrosis and the development of cardiomyopathy.

As the novel non-canonic role of $\mathrm{Na} / \mathrm{K}-\mathrm{ATP}$ ase as a signaling transducer has been recognized, more evidences suggest that $\mathrm{Na} / \mathrm{K}$ ATPase signaling components can be important molecular targets for drug development [102]. Both passive immunization against MBG $[90,91]$ and administration of anti-MBG or anti-digoxin antibodies $[85,94,130]$ have been shown to attenuate tissue fibrosis in experimental models of renal and cardiac disease. A recent study by Haller [92] showed that rapamycin, an inhibitor of Akt/mTOR pathway, can reduce the synthesis of MBG in rats and block PNx-induced cardiac fibrosis. In addition, a novel patent product called NaKtide (US8981051 B2) was developed based on the discovery that $\mathrm{Na} / \mathrm{K}$-ATPase can directly interact with Src and keep Src in inactive states [131-133]. $\mathrm{Na} / \mathrm{K}-\mathrm{ATP}$ ase binds with Src through two domain interactions, namely the A domain of $\mathrm{Na} / \mathrm{K}$-ATPase binds to the $\mathrm{SH} 2$ domain of $\mathrm{Src}$, while the $\mathrm{N}$ domain of $\mathrm{Na} / \mathrm{K}-\mathrm{ATPase}$ interact with the kinase domain of Src. When digitalis compounds bind to $\mathrm{Na} / \mathrm{K}$-ATPase, the conformation changes cause the dissociation of Src kinase domain from the $\mathrm{N}$ domain of $\mathrm{Na} / \mathrm{K}$-ATPase and subsequently activates Src. The NaKtide is a peptide product that contains a 20 -amino acid sequence derived from the $\mathrm{N}$ domain of $\mathrm{Na} / \mathrm{K}-\mathrm{ATP}$ ase $\alpha 1$ subunit. By adding a leading sequence, it is then called pNaKtide. The pNaKtide can enter into cells and largely distribute on the plasma membrane [131]. Treatment of pNaKtide is hypothesized to disrupt the direct interaction between $\mathrm{Na} / \mathrm{K}$-ATPase and Src, and therefore $\mathrm{Na} / \mathrm{K}$-ATPase can no longer transduce the extracellular signal and activate downstream signaling pathways when digitalis compounds bind to it. In vitro study showed that pNaKtide can inhibit Src tyrosine 418 phosphorylation when directly incubated with purified Src [131]. Our recent studies found 
Citation: Fan X, Xie J, Tian J (2017) Reducing Cardiac Fibrosis: Na/K-ATPase Signaling Complex as a Novel Target. Cardiovasc Pharm Open Access 6: 204. doi: 10.4172/2329-6607.1000204

that pNaKtide can block the ouabain-induced decrease in anti-fibrotic microRNA miR-29b-3p in cardiac fibroblasts [128] and significantly reduce cardiac fibrosis in mice subjected to PNx surgery by inhibiting the amplification of reactive oxygen species [93]. The latter study also showed that $\mathrm{pNaKtide}$ not only prevents $\mathrm{PNx}$-induced cardiac fibrosis but also reduces cardiac fibrosis if administered after cardiac fibrosis already developed, suggesting a reversing effect in cardiac fibrosis [93]. However, the detailed molecular mechanism by which pNaKtide reduces cardiac fibrosis remains to be further explored. Even though Src activation has been indicated to be related with increased tissue fibrosis, blocking Src activation with different methods has yield inconsistent results in reducing tissue fibrosis [134-136]. It will be interesting to test if $\mathrm{pNaKtide}$ exerts its effect on cardiac fibrosis solely through inhibition of Src, or if additional mechanisms are involved. A direct comparison between pNaKtide and generic Src inhibitors will also be an interesting area of investigation.

\section{Conclusion}

In summary, our understanding of the pathology of cardiac fibrosis as well as other organ fibrosis has been greatly advanced. Some common mechanisms and major regulators were discovered and tested in experimental models and in clinical trials which showed promising results in reducing cardiac fibrosis and related cardiac disease. However, heart failure is still the leading cause of death worldwide. Novel drugs and novel strategies such as more specific targets, or a combination of different drugs should be explored to more effectively reduce the cardiac fibrosis and improve cardiac function.

\section{Disclosures and Acknowledgement}

This work was supported by the National Institutes of Health [Grant Numbers: R01-HL-105649].

\section{References}

1. Travers JG, Kamal FA, Robbins J, Yutzey KE, Blaxall BC (2016) Cardiac Fibrosis: The Fibroblast Awakens. Circ Res 118: 1021-1040.

2. Jalil JE, Doering CW, Janicki JS, Pick R, Shroff SG, et al. (1989) Fibrillar collagen and myocardial stiffness in the intact hypertrophied rat left ventricle. Circ Res 64: 1041-1050.

3. Brilla CG, Funck RC, Rupp H (2000) Lisinopril-mediated regression of myocardial fibrosis in patients with hypertensive heart disease. Circulation 102 1388-1393.

4. Lloyd JD, Adams RJ, Brown TM, Carnethon M (2010) Heart disease and stroke statistics-2010 update: a report from the American Heart Association. Circulation 121: e46-e46.

5. Xie Z, Askari A (2002) $\mathrm{Na}(+) / \mathrm{K}(+)$-ATPase as a signal transducer. Eur $\mathrm{J}$ Biochem 269: 2434-2439.

6. Weber KT, Brilla CG (1992) Factors associated with reactive and reparative fibrosis of the myocardium. Basic Res Cardiol 87: 291-301.

7. Prabhu SD, Frangogiannis NG (2016) The Biological Basis for Cardiac Repair After Myocardial Infarction: From Inflammation to Fibrosis. Circ Res 119: 91-112.

8. Cleutjens JP, Verluyten MJ, Smiths JF, Daemen MJ (1995) Collagen remodeling after myocardial infarction in the rat heart. Am J Pathol 147: 325-338.

9. Sun Y, Weber KT (2000) Infarct scar: a dynamic tissue. Cardiovasc Res 46: 250-256.

10. Krenning G, Zeisberg EM, Kalluri R (2010) The origin of fibroblasts and mechanism of cardiac fibrosis. J Cell Physiol 225: 631-637.

11. Schnee JM, Hsueh WA (2000) Angiotensin II, adhesion, and cardiac fibrosis. Cardiovasc Res 46: 264-268.

12. Zhang $R$ (2010) C-reactive protein promotes cardiac fibrosis and inflammation in angiotensin II-induced hypertensive cardiac disease. Hypertens 55: 953-960.

13. Brilla CG (2000) Renin-angiotensin-aldosterone system and myocardial fibrosis. Cardiovasc Res 47: 1-3.
14. Shi Wen X (2006) Constitutive ALK5-independent c-Jun N-terminal kinase activation contributes to endothelin-1 overexpression in pulmonary fibrosis: evidence of an autocrine endothelin loop operating through the endothelin $A$ and $B$ receptors. Mol Cell Biol 26: 5518-5527.

15. Adiarto S, Heiden S, Vignon ZN, Nakayama K, Yagi K, et al. (2012) ET-1 from endothelial cells is required for complete angiotensin II-induced cardiac fibrosis and hypertrophy. Life Sci 91: 651-657.

16. Wang X, Guo Z, Ding Z, Khaidakov M, Lin J, et al. (2015) Endothelin-1 upregulation mediates aging-related cardiac fibrosis. J Mol Cell Cardiol 80: 101-109.

17. Leask A, Abraham DJ (2004) TGF-beta signaling and the fibrotic response FASEB J 18: 816-827.

18. Bujak M, Frangogiannis NG (2007) The role of TGF-beta signaling in myocardial infarction and cardiac remodeling. Cardiovasc Res 74: 184-195.

19. Bujak M, Ren G, Kweon HJ, Dobaczewski M, Reddy A, et al. (2007) Essential role of Smad3 in infarct healing and in the pathogenesis of cardiac remodeling. Circulation 116: 2127-2138.

20. Zhang W (2011) The development of myocardial fibrosis in transgenic mice with targeted overexpression of tumor necrosis factor requires mast cell-fibroblast interactions. Circulation 124: 2106-2116.

21. Duerrschmid C, Crawford JR, Reineke E, Taffet GE, Trial J, et al. (2013) TNF receptor 1 signaling is critically involved in mediating angiotensin-II-induced cardiac fibrosis. J Mol Cell Cardiol 57: 59-67.

22. Gordon JW, Shaw JA, Kirshenbaum LA (2011) Multiple facets of NF-kB in the heart: to be or not to NF-KB. Circ Res 108: 1122-1132.

23. Chen LF, Greene WC (2004) Shaping the nuclear action of NF-kappaB. Nat Rev Mol Cell Biol 5: 392-401.

24. Tao H, Yang JJ, Shi KH, Li J (2016) Wnt signaling pathway in cardiac fibrosis: New insights and directions. Metabolism 65: 30-40

25. Biernacka A, Frangogiannis NG (2011) Aging and Cardiac Fibrosis, in Aging Dis pp: $158-173$

26. Calderone A, Bel HS, Drapeau J, El-Helou V, Gosselin H, et al. (2006) Scar myofibroblasts of the infarcted rat heart express natriuretic peptides. J Cell Physiol 207: 165-173.

27. Tomasek JJ, Gabbiani G, Hinz B, Chaponnier C, Brown RA (2002) Myofibroblasts and mechano-regulation of connective tissue remodelling. Nat Rev Mol Cell Biol 3: 349-363.

28. Baudino TA, Carver W, Giles W, Borg TK (2006) Cardiac fibroblasts: friend or foe. Am J Physiol Heart Circ Physiol 291: 1015-1026.

29. Van Den Borne SW, Diez J, Blankesteijn WM, Verjans J (2010) Myocardial remodeling after infarction: the role of myofibroblasts. Nat Rev Cardiol 7: 30-37.

30. Morris MT (2014) Resident fibroblast lineages mediate pressure overloadinduced cardiac fibrosis. J Clin Invest 124: 2921-2934.

31. Skalli O (1986) A monoclonal antibody against alpha-smooth muscle actin: a new probe for smooth muscle differentiation. J Cell Biol 103: 2787-2796.

32. Zeisberg EM, Tarnavski O, Zeisberg M, Dorfman AL, McMullen JR, et al. (2007) Endothelial-to-mesenchymal transition contributes to cardiac fibrosis. Nat Med 13: 952-961.

33. Lijnen PJ, Petrov VV, Fagard RH (2000) Induction of cardiac fibrosis by angiotensin II. Methods Find Exp Clin Pharmacol 22: 709-723.

34. Zhu YC (1997) Effects of angiotensin-converting enzyme inhibition and angiotensin II AT1 receptor antagonism on cardiac parameters in left ventricular hypertrophy. Am J Cardiol 80: 110-117.

35. The Solvd Investigators (1991) Effect of enalapril on survival in patients with reduced left ventricular ejection fractions and congestive heart failure. The SOLVD Investigators. N Engl J Med 325: 293-302.

36. The Consensus Trial Study Group (1987) Effects of enalapril on mortality in severe congestive heart failure. Results of the Cooperative North Scandinavian Enalapril Survival Study (CONSENSUS). N Engl J Med 316: 1429-1435.

37. Hayashi M (2003) Immediate administration of mineralocorticoid recepto antagonist spironolactone prevents post-infarct left ventricular remodelling associated with suppression of a marker of myocardial collagen synthesis in patients with first anterior acute myocardial infarction. Circulation 107: 2559-2565. 
Citation: Fan X, Xie J, Tian J (2017) Reducing Cardiac Fibrosis: Na/K-ATPase Signaling Complex as a Novel Target. Cardiovasc Pharm Open Access 6: 204. doi: 10.4172/2329-6607.1000204

38. Euler G (2015) Good and bad sides of TGF $\beta$-signaling in myocardial infarction. Front Physiol 6: 66

39. Dobaczewski M, Chen W, Frangogiannis NG (2011) Transforming growth factor (TGF) $\beta$ signaling in cardiac remodeling. J Mol Cell Cardiol 51: 600-606.

40. Piera Velazquez S, Li Z, Jimenez SA (2011) Role of endothelial-mesenchymal transition (EndoMT) in the pathogenesis of fibrotic disorders. Am J Pathol 179: 1074-1080.

41. Sun M (2007) Tumor necrosis factor-alpha mediates cardiac remodeling and ventricular dysfunction after pressure overload state. Circulation 115: 1398-1407.

42. Görtzen J, Schierwagen R, Bierwolf J, Klein S, Uschner FE, et al. (2015) Interplay of Matrix Stiffness and c-SRC in Hepatic Fibrosis. Front Physiol 6: 359.

43. Massip Copiz MM, Santa Coloma TA (2016) C- Src and its role in cystic fibrosis Eur J Cell Biol 95: 401-413.

44. Yang B, Liu Z, Ning H, Zhang K, Pan D, et al. (2016) MicroRNA-21 in peripheral blood mononuclear cells as a novel biomarker in the diagnosis and prognosis of prostate cancer. Cancer Biomark 17: 223-230.

45. Van Rooij E (2006) A signature pattern of stress-responsive microRNAs that can evoke cardiac hypertrophy and heart failure. Proc Natl Acad Sci USA 103 18255-18260.

46. Ramdas, V (2013) Canonical Transforming Growth Factor-beta Signaling Regulates Disintegrin Metalloprotease Expression in Experimental Renal Fibrosis via miR-29. Am J Pathol 183: 1885-1896.

47. Cheng J, Wang Y, Wang D, Wu Y (2013) Identification of collagen 1 as a posttranscriptional target of miR-29b in skin fibroblasts: therapeutic implication for scar reduction. Am J Med Sci 346: 98-103.

48. Kwiecinski M, Noetel A, Elfimova N, Trebicka J, Schievenbusch S, et al. (2011) Hepatocyte growth factor (HGF) inhibits collagen I and IV synthesis in hepatic stellate cells by miRNA-29 induction. PLoS One 6: e24568.

49. Montgomery RL, Yu G, Latimer PA, Stack C, Robinson K, et al. (2014) MicroRNA mimicry blocks pulmonary fibrosis. EMBO Mol Med 6: 1347-1356.

50. Van Rooij E, Olson EN (2012) MicroRNA therapeutics for cardiovascular disease: opportunities and obstacles. Nat Rev Drug Discov 11: 860-872.

51. Van Rooij E, Purcell AL, Levin AA (2012) Developing microRNA therapeutics. Circ Res 110: 496-507.

52. Risteli J (1993) Radioimmunoassay for the pyridinoline cross-linked carboxyterminal telopeptide of type I collagen: a new serum marker of bone collagen degradation. Clin Chem 39: 635-640.

53. Ciulla M (1997) Echocardiographic patterns of myocardial fibrosis in hypertensive patients: endomyocardial biopsy versus ultrasonic tissue characterization. J Am Soc Echocardiogr 10: 657-664.

54. Haland TF (2016) Strain echocardiography is related to fibrosis and ventricular arrhythmias in hypertrophic cardiomyopathy. Eur Heart J Cardiovasc Imaging 17: $613-621$

55. Compton G, Nield L, Dragulescu A, Benson L, Wortmann GL (2016) Echocardiography as a Screening Test for Myocardial Scarring in Children with Hypertrophic Cardiomyopathy. Int J Pediatr 2016: 1980636

56. Mewton N, Liu CY, Croisille P, Bluemke D, Lima JA (2011) Assessment of myocardial fibrosis with cardiovascular magnetic resonance. J Am Coll Cardio 57: 891-903.

57. lles L (2008) Evaluation of diffuse myocardial fibrosis in heart failure with cardiac magnetic resonance contrast-enhanced T1 mapping. J Am Coll Cardiol 52: $1574-1580$.

58. Captopril Multicenter Research Group (1983) A placebo-controlled trial of captopril in refractory chronic congestive heart failure. J Am Coll Cardiol 2: 755763.

59. Zhong J (2010) Angiotensin-converting enzyme 2 suppresses pathological hypertrophy, myocardial fibrosis, and cardiac dysfunction. Circ 122: 717-728.

60. Kawamura M (2010) Candesartan decreases type III procollagen-N-peptide levels and inflammatory marker levels and maintains sinus rhythm in patients with atrial fibrillation. J Cardiovasc Pharmacol 55: 511-517.

61. Brilla CG (2000) Regression of myocardial fibrosis in hypertensive heart disease: diverse effects of various antihypertensive drugs. Cardiovasc Res 46 : 324-331.
62. Kosmala W (2011) A randomized study of the beneficial effects of aldosterone antagonism on LV function, structure, and fibrosis markers in metabolic syndrome. JACC Cardiovasc Imaging 4: 1239-1249.

63. Kosmala W, Przewlocka KM, Szczepanik OH, Mysiak A, Marwick TH (2013) Fibrosis and cardiac function in obesity: a randomised controlled trial of aldosterone blockade. Heart 99: 320-326.

64. Mak GJ, Ledwidge MT, Watson CJ, Phelan DM, Dawkins IR, et al. (2009) Natural history of markers of collagen turnover in patients with early diastolic dysfunction and impact of eplerenone. J Am Coll Cardiol 54: 1674-1682.

65. Roubille F, Busseuil D, Merlet N, Kritikou EA, Rhéaume E, et al. (2014) Investigational drugs targeting cardiac fibrosis. Expert Rev Cardiovasc Ther 12: $111-125$.

66. Lijnen PJ, Petrov VV, Fagard RH (2000) Induction of cardiac fibrosis by transforming growth factor-beta(1). Mol Genet Metab 71: 418-435.

67. Eghbali M (1991) Differential effects of transforming growth factor-beta 1 and phorbol myristate acetate on cardiac fibroblasts. Regulation of fibrillar collagen mRNAs and expression of early transcription factors. Circ Res 69: 483-490.

68. Chua CC (1991) Effect of growth factors on collagen metabolism in cultured human heart fibroblasts. Connect Tissue Res 26: 271-281.

69. Cucoranu I, Clempus R, Dikalova A, Phelan PJ, Ariyan S, et al. (2005) NAD(P) $\mathrm{H}$ oxidase 4 mediates transforming growth factor-beta1-induced differentiation of cardiac fibroblasts into myofibroblasts. Circ Res 97: 900-907.

70. Butz H, Rácz K, Hunyady L, Patócs A (2012) Crosstalk between TGF $\beta$ signaling and the microRNA machinery. Trends Pharmacol Sci 33: 382-393.

71. Meng XM, Nikolic PDJ, Lan HY (2016) TGFß: the master regulator of fibrosis Nat Rev Nephrol 12: 325-338

72. Xavier S, Piek E, Fujii M, Javelaud D, Mauviel A, et al. (2004) Amelioration of radiation-induced fibrosis: inhibition of transforming growth factor-beta signaling by halofuginone. J Biol Chem 279: 15167-15176.

73. King TE, Bradford WZ, Castro BS, Fagan EA, Glaspole I, et al. (2014) A phase 3 trial of pirfenidone in patients with idiopathic pulmonary fibrosis. N Engl J Med 370: 2083-2092

74. Pitt B (1999) The effect of spironolactone on morbidity and mortality in patients with severe heart failure. Randomized Aldactone Evaluation Study Investigators. N Engl J Med 341: 709-717.

75. Abbas S (2015) Risk of hyperkalemia and combined use of spironolactone and long-term ACE inhibitor/angiotensin receptor blocker therapy in hear failure using real-life data: a population- and insurance-based cohort Pharmacoepidemiol Drug Saf 24: 406-413.

76. Borghi C (1993) Evidence of a partial escape of renin-angiotensin-aldosterone blockade in patients with acute myocardial infarction treated with ACE inhibitors. J Clin Pharmacol 33: 40-45.

77. Biollaz J, Brunner HR, Gavras I, Waeber B, Gavras H (1982) Antihypertensive therapy with MK 421: angiotensin II--renin relationships to evaluate efficacy of converting enzyme blockade. J Cardiovasc Pharmacol 4: 966-972.

78. Tian J (2003) Spironolactone attenuates experimental uremic cardiomyopathy by antagonizing marinobufagenin. Hypertension 54: 1313-1320.

79. Von Lueder TG, Wang BH, Kompa AR, Huang L, Webb R, et al. (2015) Angiotensin receptor neprilysin inhibitor LCZ696 attenuates cardiac remodeling and dysfunction after myocardial infarction by reducing cardiac fibrosis and hypertrophy. Circ Heart Fail 8: 71-78.

80. McMurray JJ, Packer M, Desai AS, Gong J, Lefkowitz MP, et al. (2014) Angiotensin-neprilysin inhibition versus enalapril in heart failure. N Engl J Med 371: 993-1004

81. Cruden NL (2004) Neutral endopeptidase inhibition augments vascular actions of bradykinin in patients treated with angiotensin-converting enzyme inhibition. Hypertension 44: 913-918.

82. Rademaker MT (1996) Neutral endopeptidase inhibition: augmented atrial and brain natriuretic peptide, haemodynamic and natriuretic responses in ovine heart failure. Clin Sci (Lond) 91: 283-291.

83. Wilkinson IB (2001) Adrenomedullin (ADM) in the human forearm vascula bed: effect of neutral endopeptidase inhibition and comparison with proadrenomedullin NH2-terminal 20 peptide (PAMP). Br J Clin Pharmacol 52 $159-1564$ 
Citation: Fan X, Xie J, Tian J (2017) Reducing Cardiac Fibrosis: Na/K-ATPase Signaling Complex as a Novel Target. Cardiovasc Pharm Open Access 6: 204. doi: 10.4172/2329-6607.1000204

Page 6 of 7

84. Shapiro JI, Tian J (2011) Signaling through the Na/K-ATPase: implications for cardiac fibrosis. American journal of physiology. Heart and Circulatory Physiology 300: 29-30.

85. Wansapura AN (2011) Mice expressing ouabain-sensitive alpha1-Na,K ATPase have increased susceptibility to pressure overload-induced cardiac hypertrophy. Am J Physiol Heart Circ Physiol 300: 347-355.

86. Liu J (2012) Reactive Oxygen Species Modulation of Na/K-ATPase Regulates Fibrosis and Renal Proximal Tubular Sodium Handling. Int J Nephrol, p: 381320 .

87. Fedorova LV (2009) The cardiotonic steroid hormone marinobufagenin induces renal fibrosis: implication of epithelial-to-mesenchymal transition. Am J Physiol Renal Physiol 296: 922-934.

88. Kennedy DJ, Elkareh J, Shidyak A, Shapiro AP, Smaili S, et al. (2008) Partial nephrectomy as a model for uremic cardiomyopathy in the mouse. Am J Physiol Renal Physiol 294: 450-454.

89. Kennedy DJ, Malhotra D, Shapiro JI (2006) Molecular insights into uremic cardiomyopathy: cardiotonic steroids and $\mathrm{Na} / \mathrm{K}$ ATPase signaling. Cell Mol Biol (Noisy-le-grand) 52: 3-14

90. Elkareh J (2014) Marinobufagenin stimulates fibroblast collagen production and causes fibrosis in experimental uremic cardiomyopathy. Hypertension 49 : $215-224$

91. Haller ST (2014) Passive immunization against marinobufagenin attenuates renal fibrosis and improves renal function in experimental renal disease. Am J Hypertens 27: 603-609.

92. Haller ST (2016) Rapamycin Attenuates Cardiac Fibrosis in Experimental Uremic Cardiomyopathy by Reducing Marinobufagenin Levels and Inhibiting Downstream Pro-Fibrotic Signaling. J Am Heart Assoc 5.

93. Liu J (2016) Attenuation of Na/K-ATPase Mediated Oxidant Amplification with pNaKtide Ameliorates Experimental Uremic Cardiomyopathy. Sci Rep 6: 34592.

94. Haller ST (2012) Monoclonal antibody against marinobufagenin reverses cardiac fibrosis in rats with chronic renal failure. Am J Hypertens 25: 690-696.

95. Skou JC (1957) The influence of some cations on an adenosine triphosphatase from peripheral nerves. Biochim Biophys Acta 23: 394-401.

96. Kanai R, Ogawa H, Vilsen B, Cornelius F, Toyoshima C (2013) Crystal structure of a $\mathrm{Na}+-$ bound $\mathrm{Na}^{+}, \mathrm{K}^{+}$-ATPase preceding the E1P state. Nature 502: 201-206.

97. Sweadner KJ, Donnet C (2001) Structural similarities of Na, K-ATPase and SERCA, the $\mathrm{Ca}(2+)-A T P a s e$ of the sarcoplasmic reticulum. Biochem $\mathrm{J} 356$ : 685-704.

98. Lingrel JB (1992) Na, K-ATPase: isoform structure, function, and expression. J Bioenerg Biomembr 24: 263-270.

99. Aperia A, Akkuratov EE, Fontana JM, Brismar H (2016) Na+-K+-ATPase a new class of plasma membrane receptors. Am J Physiol Cell Physiol 310: C491-C495.

100. Xie Z (2003) Molecular mechanisms of $\mathrm{Na} / \mathrm{K}-\mathrm{ATP}$ ase-mediated signal transduction. Ann N Y Acad Sci 986: 497-503.

101. Xie Z (2001) Ouabain interaction with cardiac Na/K-ATPase reveals that the enzyme can act as a pump and as a signal transducer. Cell Mol Biol (Noisyle-grand) 47: 383-390.

102. Xie Z, Xie J (2005) The Na/K-ATPase-mediated signal transduction as a target for new drug development. Front Biosci 10: 3100-3109.

103. Li J (2006) Low doses of ouabain protect from serum deprivation-triggered apoptosis and stimulate kidney cell proliferation via activation of NF-kappaB. J Am Soc Nephrol 17: 1848-1857.

104. Aizman O, Aperia A (2003) Na, K-ATPase as a signal transducer. Ann N Y Acad Sci 986: 489-496

105. Tian J, Li X, Liang M, Liu L, Xie JX, et al. (2009) Changes in sodium pump expression dictate the effects of ouabain on cell growth. J Biol Chem 284 14921-14929.

106. Abramowitz J (2003) Ouabain- and marinobufagenin-induced proliferation of human umbilical vein smooth muscle cells and a rat vascular smooth muscle cell line, A7r5. Circulation 108: 3048-3053.

107. Chen KK, Kovaríková A (1967) Pharmacology and toxicology of toad venom J Pharm Sci 56: 1535-1541.
108. Braunwald E, Klocke FJ (1965) Digitalis. Ann Rev Med 16: 371-386.

109. McDonough AA, Wang J, Farley RA (1995) Significance of sodium pump isoforms in digitalis therapy. J Mol Cell Cardiol 27: 1001-1009.

110. Bagrov AY, Shapiro JI, Fedorova OV (2009) Endogenous Cardiotonic Steroids: Physiology, Pharmacology, and Novel Therapeutic Targets. Pharmacol Rev, pp: 9-38.

111. Simonini M, Pozzoli S, Bignami E, Casamassima N, Messaggio E, et al (2015) Endogenous Ouabain: An Old Cardiotonic Steroid as a New Biomarker of Heart Failure and a Predictor of Mortality after Cardiac Surgery. Biomed Res Int 2015: 714-793.

112. Hamlyn JM, Blaustein MP, Bova S, DuCharme DW, Harris DW, et al. (1991) Identification and characterization of a ouabain-like compound from human plasma. Proc Natl Acad Sci USA 88: 6259-6263.

113. Fedorova OV, Doris PA, Bagrov AY (1998) Endogenous marinobufagenin-like factor in acute plasma volume expansion. Clin Exp Hypertens 20: 581-591.

114. Bagrov AY, Shapiro JI (2008) Endogenous digitalis: pathophysiologic roles and therapeutic applications. Nat Clin Pract Nephrol 4: 378-392.

115. Gonick HC (1998) Simultaneous measurement of marinobufagenin, ouabain and hypertension-associated protein in various disease states. Clin Exp Hypertens 20: 617-627.

116. Bagrov AY (1995) Endogenous marinobufagenin-like immunoreactive factor and $\mathrm{Na}+, \mathrm{K}+$ ATPase inhibition during voluntary hypoventilation. Hypertension 26: 781-788.

117. Gottlieb SS, Rogowski AC, Weinberg M, Krichten CM, Hamilton BP, et al (1992) Elevated concentrations of endogenous ouabain in patients with congestive heart failure. Circulation 86: 420-425.

118. Tian J (2010) Renal ischemia regulates marinobufagenin release in humans. Hypertension 56: 914-919.

119. Lopatin DA, Ailamazian EK, Dmitrieva RI, Shpen VM, Fedorova OV, et al. (1999) Circulating bufodienolide and cardenolide sodium pump inhibitors in preeclampsia. J Hypertens 17: 1179-1187.

120. Bagrov AY, Fedorova OV, Dmitrieva RI, Howald WN, Hunter AP, et al. (1998) Characterization of a urinary bufodienolide $\mathrm{Na}+\mathrm{K}+$-ATPase inhibitor in patients after acute myocardial infarction. Hypertension 31: 1097-1103.

121. Bagrov AY, Kuznetsova EA, Fedorova OV (1994) Endogenous digoxin-like factor in acute myocardial infarction. J Intern Med 235: 63-67.

122. Clerico A, Giampietro O (1990) Is the endogenous digitalis-like factor the link between hypertension and metabolic disorders as diabetes mellitus, obesity and acromegaly. Clin Physiol Biochem 8: 153-168.

123. Straub RH (1996) Atrial natriuretic factor and digoxin-like immunoreactive factor in diabetic patients: their interrelation and the influence of the autonomic nervous system. J Clin Endocrinol Metab 81: 3385-3389.

124. Hamlyn JM, Blaustein MP (2016) Endogenous Ouabain: Recent Advances and Controversies. Hypertension 68: 526-532.

125. Kennedy DJ (2006) Central role for the cardiotonic steroid marinobufagenin in the pathogenesis of experimental uremic cardiomyopathy. Hypertension 47: 488-495

126. Elkareh J (2009) Marinobufagenin induces increases in procollagen expression in a process involving protein kinase $\mathrm{C}$ and Fli-1: implications fo uremic cardiomyopathy. Am J Physiol Renal Physiol 296: 1219-1226.

127. Ladykowska JC, Shirasaki F, Jackers P, Watson DK, Trojanowska M (2001) Fli-1 inhibits collagen type I production in dermal fibroblasts via an Sp1dependent pathway. J Biol Chem 276: 20839-20848.

128. Drummond CA (2016) Na/K-ATPase signaling regulates collagen synthesis through microRNA-29b-3p in cardiac fibroblasts. Physiol Genomics 48: 220-229.

129. La J, Reed EB, Koltsova S, Akimova O, Hamanaka RB, et al. (2016) Regulation of myofibroblast differentiation by cardiac glycosides. Am J Physiol Lung Cell Mol Physiol 310: 815-823

130. Grigorova YN (2016) Aortic Fibrosis, Induced by High Salt Intake in the Absence of Hypertensive Response, is Reduced by a Monoclonal Antibody to Marinobufagenin. Am J Hypertens 29: 641-646.

131. Li Z (2009) NaKtide, a Na/K-ATPase-derived peptide Src inhibitor, antagonizes ouabain-activated signal transduction in cultured cells. The J Biol Chem 284 21066-21076. 
Citation: Fan X, Xie J, Tian J (2017) Reducing Cardiac Fibrosis: Na/K-ATPase Signaling Complex as a Novel Target. Cardiovasc Pharm Open Access 6: 204. doi: 10.4172/2329-6607.1000204

132. Li Z (2011) Na/K-ATPase mimetic pNaKtide peptide inhibits the growth of human cancer cells. J Biol Chem 286: 32394-32403.

133. Tian J, Cai T, Yuan Z, Wang H, Liu L, et al. (2006) Binding of Src to $\mathrm{Na}+$ K+-ATPase forms a functional signaling complex. Mol Biol Cell 17: 317-326.

134. Zhou D, Liu Y (2016) Therapy for kidney fibrosis: is the Src kinase a potential target? Kidney Int 89: 12-14.
135. Hu M, Che P, Han X, Cai GQ, Liu G, et al. (2014) Therapeutic targeting of SRC kinase in myofibroblast differentiation and pulmonary fibrosis. J Pharmacol Exp Ther 351: 87-95.

136. Callera GE (2016) c-Src Inhibition Improves Cardiovascular Function but not Remodeling or Fibrosis in Angiotensin II-Induced Hypertension. Hypertension 68: $1179-1190$ 